\title{
Three-dimensional Hi-Vision System for Microneurosurgical Documentation Based on Wide-vision Telepresence System Using One Camera and One Monitor
}

\author{
Hiroshi OKudERA, Shigeaki KobayaSHI, Kazuhiko Kyoshima, \\ Hiroshi SAITO* and Ryo MOCHIZUKI** \\ Department of Neurosurgery, Shinshu University School of Medicine, Matsumoto, \\ Nagano; *Nagashima Medical Instrument Corporation, Tokyo; \\ ${ }^{* *}$ Media International Corporation, Tokyo
}

\begin{abstract}
A three-dimensional (3-D) high-definition television (Hi-Vision) system suitable for attachment to a stereoscopic operating microscope allowing 3-D medical documentation using one Hi-Vision camera and one Hi-Vision monitor is described. The system provides 3-D high-definition microneurosurgical recorded images suitable for viewing on a screen or monitor, or for printing.
\end{abstract}

Key words: three-dimensional imaging, documentation, microsurgery, high-definition television, Hi-Vision

\section{Introduction}

The Hi-Vision system is a new high-definition television (HDTV) technology intended to replace the $\mathrm{Na}-$ tional Television System Committee (NTSC) system. HDTV provides images of superb quality with a greater resolution than NTSC systems by using 1125 instead of 525 scanning lines. ${ }^{2)}$ In 1987 , we reported the first use of the Hi-Vision system in the medical field for relaying and recording neurosurgical procedures under the operating microscope." Stereoscopic recording and presentation were achieved using two Hi-Vision cameras and recorders in $1988{ }^{8}{ }^{8}$ However, the cost performance and the size of the system including the camera unit, recorder and monitor were unsuitable for clinical use. ${ }^{8.9}$ With more recent technological innovations, the Hi-Vision system has become smaller and cheaper.

Here, we propose a three-dimensional (3-D) $\mathrm{Hi}$ Vision system for microneurosurgical documentation based on the wide-vision telepresence system using one camera and one monitor. ${ }^{7)}$ Technical details of the system and illustrative stereoscopic images are demonstrated.

Received May 13, 1993; Accepted June 18, 1993

\section{Equipment and Method}

The 3-D Hi-Vision documentation system is based on the wide-vision telepresence system using one camera and one monitor ${ }^{7)}$ (developed by Media International Corp., Tokyo).

A 3-D device (manufactured by Nagashima Medical Instrument Corp., Tokyo) for attachment

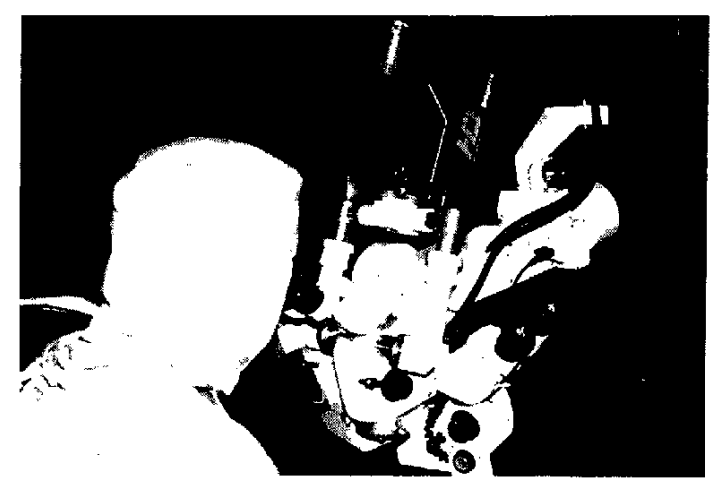

Fig. 1 3-D attachment device with Hi-Vision camera installed on the stereoscopic operating microscope. 


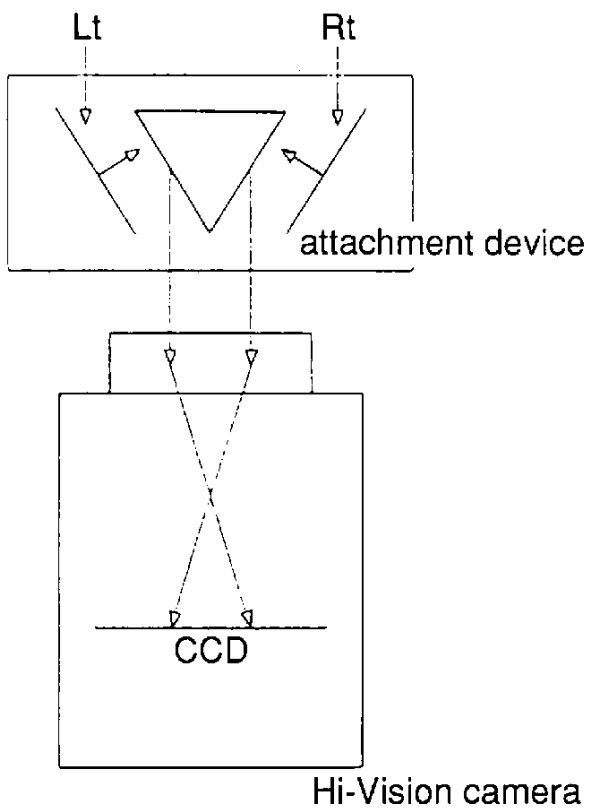

Fig. 2 Schematic drawing of the 3-D Hi-Vision system using one camera and one monitor: the wide-vision telepresence system. CCD: charge coupled device.

to the stereoscopic operating microscope (Mizuho Ikakogyo Co., Tokyo) was especially developed (Fig. 1). The device conducts the right and left outputs of the stereoscopic operating microscope ${ }^{14)}$ to one visual field individually. Figure 2 shows the schematic drawing of the 3-D attachment device and system design. A new light $\mathrm{Hi}$-Vision camera using charge coupled device, weighing $2 \mathrm{~kg}$, was connected to this system. The camera and 3-D device caused no hindrance to surgical procedures.

The Hi-Vision system uses a height:width ratio of $9: 16,{ }^{2)}$ so bilateral images can be recorded simultaneously in one Hi-Vision image. The recorded Hi-Vision images can be observed using a conventional parallel stereoscopic method or viewer, or to provide 3-D documentation of microneurosurgery on a monitor or screen using a video projector or in printed matter.

\section{Illustrative Case}

A 62-year-old female underwent clipping of a ruptured right middle cerebral artery (MCA) aneurysm 1 year ago. At that time, angiograms also showed unruptured multiple aneurysms at the left MCA and basilar bifurcation. A second operation was planned to clip the MCA and basilar bifurcation aneurysms.

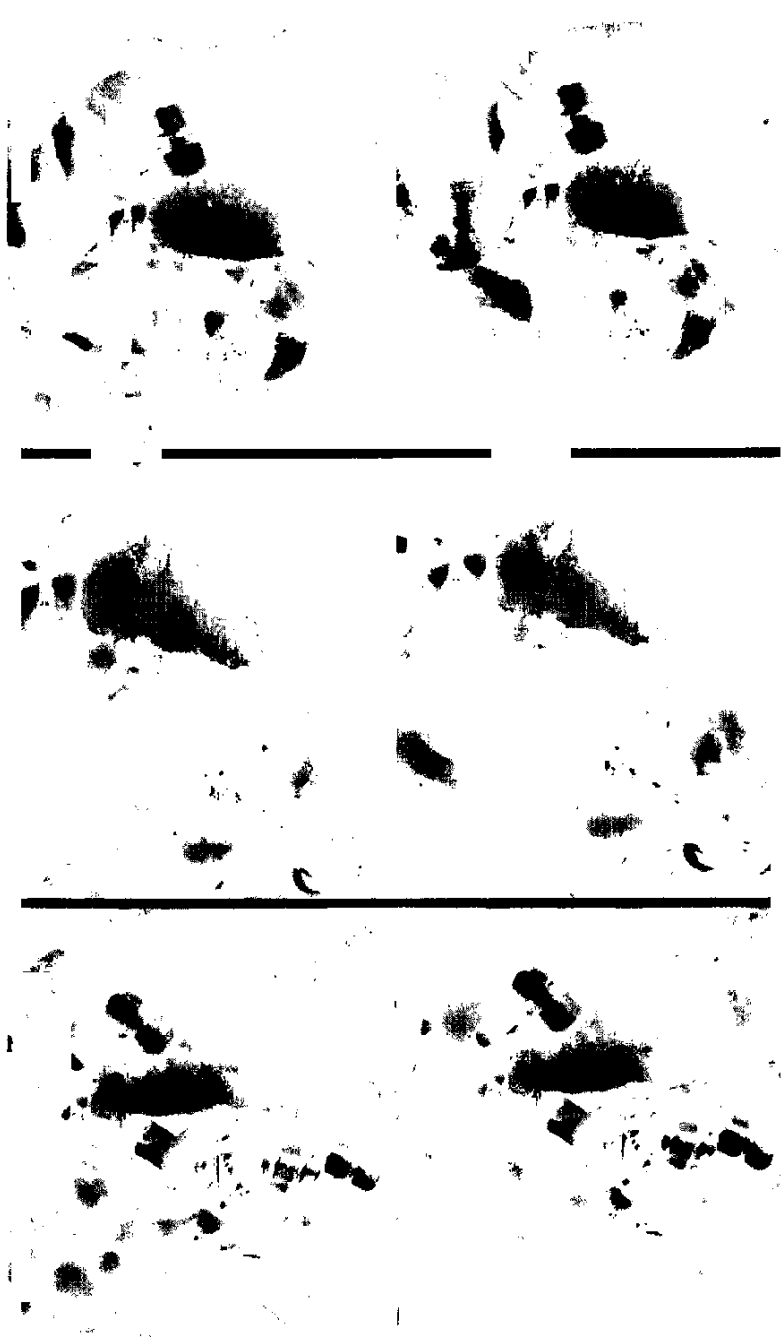

Fig. 3 Hi-Vision stereograms printed directly from the recorded 3-D Hi-Vision images. Clipping of the basilar bifurcation aneurysm via the left opticocarotid space (upper), and clipping of the left MCA aneurysm with the L-shaped clip (middle) and the short ring clip (lower) can be seen using a parallel eye method without optical devices.

A left frontotemporal craniotomy was performed with her in the supine position. The Sylvian fissure was opened proximally and dissected distally to locate the MCA aneurysm. After exposing the aneurysm, the basilar system was approached. The basilar aneurysm was identified in the opticocarotid space, and clipped with a straight $20 \mathrm{~mm}$ Sugita clip (Fig. 3 upper). The MCA aneurysm was then exposed and clipped with an L-shaped clip (Fig. 3 middle) and a short ring clip (Fig. 3 lower). 


\section{Discussion}

Visual documentation using television and video systems is very important in modern medical practice, especially for the education of medical students, ${ }^{4)}$ the training of residents ${ }^{5,12)}$ and records for medical conferences. ${ }^{3)}$ For the documentation of microsurgery ${ }^{6,11,13,15)}$ and endoscopic surgery, ${ }^{1,10)}$ the video system is essential.

The printed images taken from the recordings by our Hi-Vision system of the illustrative case clearly demonstrate the high quality and definition achieved, which are comparable to that of $35 \mathrm{~mm}$ movie film. As the system only requires one camera and one recorder, the cost performance and size make it very suitable for microsurgical and endoscopic documentation.

\section{References}

1) Cannon CR: Video documentation of endoscopic sinus surgery. Otolaryngol Head Neck Surg 101: 629632, 1989

2) Fujio T: High-definition television systems. Proc IEEE 73: 646-655, 1985

3) Kalisman $M$, Wendorff ER, Millendorf JB: Video conferencing and real-time communication. Clin Plast Surg 13: 497-507, 1986

4) Katzenberg B, Hirsch B, Piela P, Faett J, Durrant JD: Development of an educational module for surgical training: A case study. $J$ Audiov Media Med 12: $147-152,1989$

5) May M, Korzec KR, Mester SJ: Video telescopic sinus surgery technique for teaching. Trans Pa Acad Ophthalmol Otolaryngol 42: 1037-1039, 1990

6) McCartney DL: Dual camera sequencer for microsurgical documentation. Ophthalmic Surg 21: 860-861, 1990

7) Mochizuki R: Wide-vision telepresence (Hi-Vision one camera one monitor 3D system). Sanjigen Eizo 6:
55-58, 1992 (in Japanese)

8) Okudera H, Kobayashi S, Takemae T, Kyoshima K, Gibo H, Shibuya M, Sugita K: Introduction of high definition television system to neurosurgical documentation. Neurol Res 14: 386-388, 1992

9) Okudera H, Kobayashi S, Takemae T, Sugita K: Stereoscopic HDTV (high definition TV) projection system for use with the operating microscope, in Sugita K, Shibuya M (eds): Intracranial Aneurysms and Arteriovenous Malformation. Nagoya, Nagoya University Press, 1990, pp 411-412

10) Satava RM, Gooden SM: The impact of video endoscopy on surgical training. Am Surg 55: 263-266, 1989

11) Selkin SG: Photodocumentation of laser microsurgery: Preoperative, and postoperative techniques for still and video photographs. Otolaryngol Head Neck Surg 95: 259-272, 1986

12) Smeak DD, Beck ML, Shaffer CA, Gregg CG: Evaluation of video tape and a simulator for instruction of basic surgical skills. Vet Surg 20: 30-36, 1991

13) Sugita K, Ohohigashi Y, Kobayashi S: Stereoscopic television system for use with the operating microscope. Technical note. J Neurosurg 62: 610611,1985

14) Sugita $K$, Tsugane $R$ : Triplescope for neurosurgery (Nagashima II), in Koos WT, Bock FW, Spetzler RF (eds): Clinical Microneurosurgery. Stuttgart, Georg Thieme, 1976, pp 5-6

15) Yanagisawa E, Horowitz JB, Yanagisawa K, Mambrino LJ: Comparison of new telescopic video microlaryngoscopic and standard microlaryngoscopic techniques. Ann Otol Rhinol Laryngol 101: $51-60,1992$

Address reprint requests to: H. Okudera, M.D., Department of Neurosurgery, Shinshu University School of Medicine, 3-1-1 Asahi, Matsumoto, Nagano 390, Japan. 